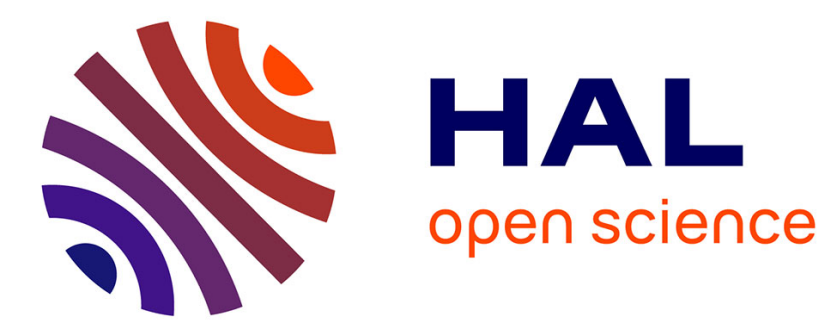

\title{
Dissipated energy in dry and wet plasters
}

\author{
Sylvain Meille, Pascal Reynaud, Malika Saadaoui, Gilbert Fantozzi
}

\section{To cite this version:}

Sylvain Meille, Pascal Reynaud, Malika Saadaoui, Gilbert Fantozzi. Dissipated energy in dry and wet plasters. Defect and Diffusion Forum, 2002, 206-207, pp.171-174.

10.4028/www.scientific.net/DDF.206-207.171 . hal-00587076

\section{HAL Id: hal-00587076 \\ https://hal.science/hal-00587076}

Submitted on 21 Jan 2022

HAL is a multi-disciplinary open access archive for the deposit and dissemination of scientific research documents, whether they are published or not. The documents may come from teaching and research institutions in France or abroad, or from public or private research centers.
L'archive ouverte pluridisciplinaire HAL, est destinée au dépôt et à la diffusion de documents scientifiques de niveau recherche, publiés ou non, émanant des établissements d'enseignement et de recherche français ou étrangers, des laboratoires publics ou privés.

\section{(ㄷ)(1) $\$$}

Distributed under a Creative Commons Attribution - NonCommercial| 4.0 International 


\title{
Dissipated Energy in Dry and Wet Plasters
}

\author{
S.Meille ${ }^{1}$, P.Reynaud ${ }^{1}$, M.Saadaoui ${ }^{2}$ and G.Fantozzi ${ }^{1}$ \\ ${ }^{1}$ GEMPPM-UMR CNRS 5510, INSA de Lyon, \\ 20 Avenue Albert Einstein, 69621 Villeurbanne, France \\ ${ }^{2}$ LERSIM, Ecole Mohammadia d'Ingénieurs, \\ BP765 Agdal, Rabat, Morocco
}

Keywords: Damping, Moisture, Plaster

\begin{abstract}
It is well known that the mechanical properties of wet plaster are lower than those of dry plaster, but the origin of this phenomenon is not well understood. Mechanical spectroscopy has been chosen to characterise the contacts between crystals in set plaster. These experiments have shown that this contact can be described by a slipper, with a threshold dependent on the content of moisture in plaster.
\end{abstract}

\section{Introduction}

Plaster is a common material used for constructions. Many works have been carried on processing of plaster, but few studies have been carried on the mechanical behaviour of plaster.

This material is an hydraulic binder characterised by a linear elastic macroscopic mechanical behaviour when it is dry. It becomes non linear, and its mechanical strength drops drastically in wet environment. This result is well known [1], but its physical origin is not well understood.

The objective of this work is to use mechanical spectroscopy to characterise the plasticity of plaster induced by water in relation with the microstructural mechanisms involved.

\section{Materials and Method}

The plaster studied in this work is a Selecta $\beta$ hemi-hydrate hydrated at a water on plaster ratio of 0.8 .

The microstructure of this material is characterised by a network of tangled needles of gypsum $\left(\mathrm{CaSO}_{4}, 2 \mathrm{H}_{2} \mathrm{O}\right)$, as shown on Fig. 1. During fracture, the needles are always debonded and not broken, suggesting that the sliding between needles in contact is certainly an important parameter to consider.

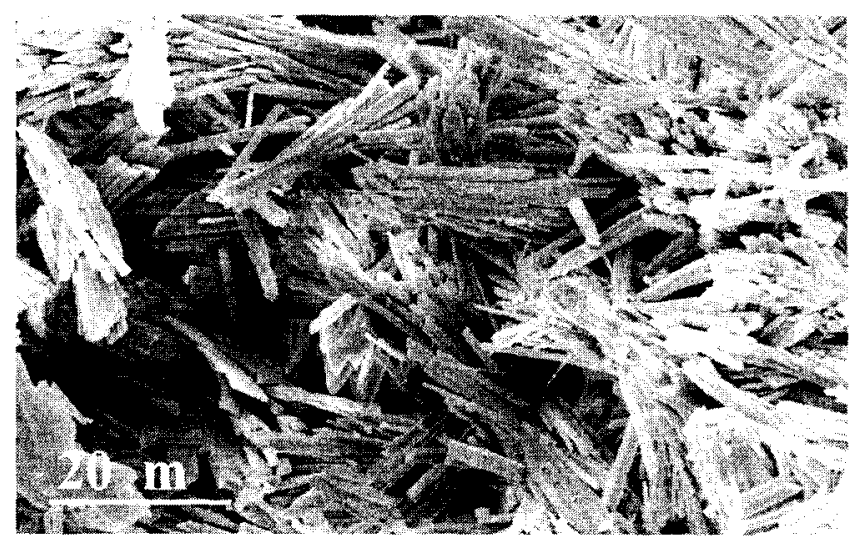

Figure 1: Microstructure of a dry plaster (fracture surface). 


\section{Experimental Procedure}

Two methods have been used to measure internal friction: torsion and flexion techniques. Torsion pendulum allows measurement of high amplitude of deformation (up to $4.10^{-3}$ ) at low frequency (about $1 \mathrm{~Hz}$ ) [2]. The specimen used in this system is a dog-bone specimen with a central part of $2 \times 5 \times 2 \mathrm{~mm}^{3}$, and a total length lower than $40 \mathrm{~mm}$ (Fig. 2). The stress is applied by electromagnetic coils and the deformation is measured optically.

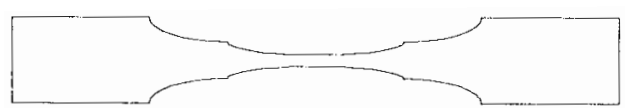

Figure 2: Specimen used in torsion pendulum (central part: $2 \times 5 \times 2 \mathrm{~mm}^{3}$ ).

Flexion apparatus is a resonant system which allows a loading at high frequency (about $1 \mathrm{kHz}$ ) but with low amplitude of deformation (about $10^{-6}$ ). The specimens are parallelepipedic with a total dimension of $40 \times 5 \times 1 \mathrm{~mm}^{3}$.

Both type of specimens are moulded, and no machining is required.

The main results presented here were obtained on torsion pendulum by varying the amplitude of deformation at a constant frequency. The temperature was also constant whereas the water content and the pressure (atmosphere pressure or low vacuum) have been changed.

\section{Experimental results}

The experiments have been carried out at various relative humidity [3], including extreme conditions (dry plaster under low vacuum, and wet plaster saturated with water).

Under vacuum, the internal friction is low and independent on the level of loading. When the relative humidity increases $(35 \%, 70 \%)$ the internal friction increases, and exhibit two stages (Fig. 3 ): a first stage for low amplitudes where internal friction is nearly constant, and a second stage for high amplitudes where internal friction increases linearly with the amplitude of deformation. This type of evolution is also observed in wet plaster, and in that case the level of internal friction is higher.

An important observation is that the level of internal friction depends only on the relative humidity, and is completely reversible.

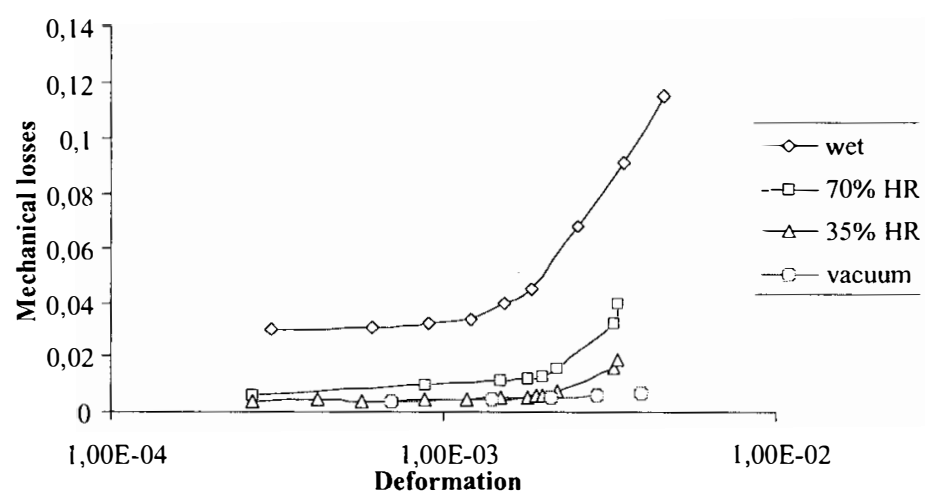

Figure 3: Internal friction in plaster at various content of water (torsion pendulum). 
A comparison has also been made between water and ethanol (Fig. 4). When plaster is saturated with ethanol, the evolution of the internal friction with the amplitude of deformation is similar to that observed when plaster is saturated with water.

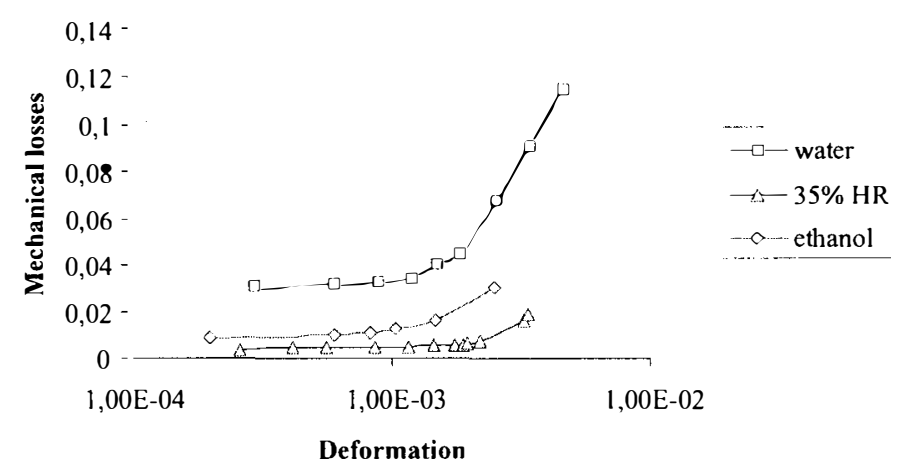

Figure 4: Internal friction in plaster wetted by water and ethanol (torsion pendulum).

In order to understand if plasticity in wet plaster is a specific phenomenon due to this extreme condition, experiments have been carried out on resonant flexion apparatus at various relative humidities. These experiments show that internal friction increases progressively from dry plaster to wet plaster. Hence the phenomenon of plasticity observed on wet plaster occurs also on plasters in moist atmospheres but is more or less developed in accordance with the relative humidity.

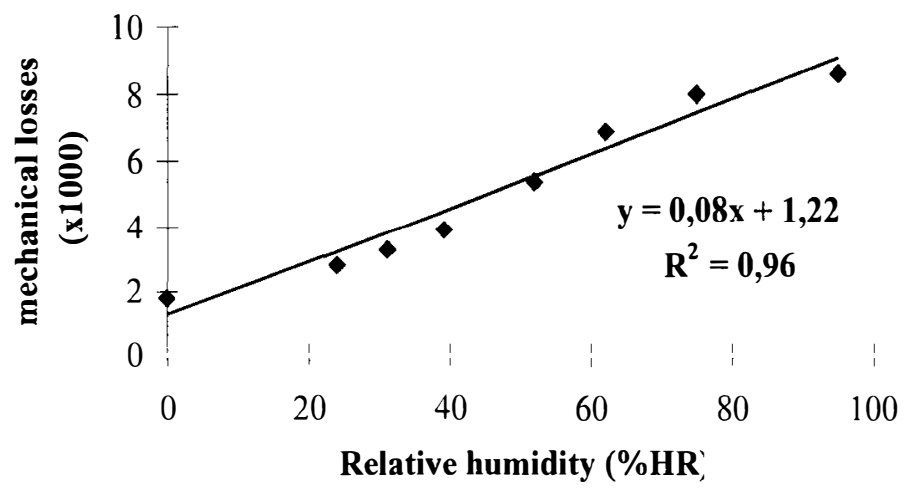

Figure 5: Internal friction in plaster in relation with the content of water (flexion pendulum).

\section{Discussion}

When the plaster is wet, a thin layer of water molecules can be introduced between gypsum needles in the zones in contact [4]. The plasticity can thus be explained by a sliding of needles induced by water. This can be described, to simplify, by a Saint-Venant Model with a spring of modulus E, and a slipper with a threshold $\sigma_{0}$. If a cyclic deformation of amplitude $\varepsilon_{\max }$ is applied, the internal friction is zero when the amplitude is lower than $\sigma_{0} / \mathrm{E}$, and increases linearly for higher amplitudes. But due to the water absorbed, a non zero damping is measured on wet plasters even at low amplitudes (Fig. 3 and 4). This phenomenon has been observed on many porous materials [5-9]. Hence to take into account this effect, a dashpot (with a viscosity $\eta$ ) has to be added in order to 
improve the Saint-Venant model (Fig. 6). In that case, the internal friction is given by the following expressions, in a good agreement with the experimental results (Fig. 3 and Fig. 4):

$$
\begin{array}{ll}
\frac{\Delta \mathrm{W}}{\mathrm{W}_{\mathrm{E}}}=\frac{\mathrm{TE}}{\eta} & \text { for } \varepsilon_{\max }<\frac{\sigma_{0}}{\mathrm{E}}+\frac{\sigma_{0}}{\eta \omega}\left(1+\frac{\mathrm{E}}{\eta \omega}\right) \\
\frac{\Delta \mathrm{W}}{\mathrm{W}_{\mathrm{E}}} \approx \frac{\mathrm{TE}}{\eta}+8\left(\frac{\mathrm{E}}{\sigma_{0}} \varepsilon_{\max }-1\right) & \text { for } \varepsilon_{\max }>\frac{\sigma_{0}}{\mathrm{E}}+\frac{\sigma_{0}}{\eta \omega}\left(1+\frac{E}{\eta \omega}\right)
\end{array}
$$

where $T$ is the period of the cycle of deformation and $\omega=\frac{2 \pi}{T}$.

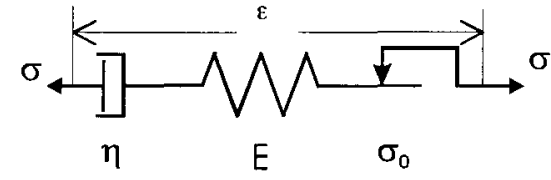

Figure 6: Model proposed to describe the internal friction in wet plasters.

The experimental results of Figure 3 and Figure 4 indicate that the viscosity $\eta$, the modulus $E$ and the threshold $\sigma_{0}$ in expressions ( $\mathrm{la}$ ) and ( $\mathrm{lb}$ ) are both dependent on the level of relative humidity. The evolutions observed on plaster have also been measured on other materials like sandstone for example [10]. In that case friction between the grains can also be described by the Saint-Venant model.

\section{Conclusion}

As shown on the micrograph (Fig. 1), the microstructure of the plaster is a network of fine and tangled needles of gypsum.

When an increasing amplitude of loading is applied to plaster, the dissipated energy is constant below a limit value of the amplitude of deformation, then increases linearly. This variation is enhanced when the relative humidity increases, and depends only on the relative humidity level.

This phenomenon indicates that the type of friction between adjacent gypsum needles can be modelled by a slipper with a threshold which depends on moisture.

\section{References}

[1] H. Andrews: $J^{\text {al }}$ of the Society of Chemical Industry. Vol. 5 (1946), pp. 125-28.

[2] S.Etienne, J.Y. Cavaille, J. Perez, R. Point and M. Salvia: Rev. Sci. Instrum. Vol. 53, Ni8 (1982), pp. 1261-1266.

[3] S. Meille: PhD Thesis (2001), 203 pp.

[4] J. Chappuis: Colloids and Surface Vol. 156, Ni 1-3 (1999), pp. 223-241.

[5] B.R. Tittmann, V.A. Clark, J.M. Richardson and T.W. Spencer: Journal of Geophysical Research Vol. 85, Ni B10 (1980), pp. 5199-5208.

[6] G.M. Pharr and M.F. Ashby: Acta metall Vol. 31 (1983), pp. 129-138.

[7] W.F. Murphy, K.W. Winkler and R.L. Kleinberg: Geophysical Research Letters Vol. $1, \mathrm{~N}_{i} 9$ (1984), pp. 805-808.

[8] T. Baykara and G.M. Pharr: Acta metall. mater. Vol. 39, Ni6 (1991), pp. 1141-1150.

[9] J. Lepage and J. Menaucourt: Journal of Materials Science Vol. 33 (1998), pp. 2905-2917.

[10] G. Mavko: Journal of Geophysical Research Vol. 84, NiB9 (1979), pp. 4769-4775. 